\title{
Continuing Professional Development (CPD); What should we do?
}

\author{
A Whohab Khan, Associate Professor, Department of Surgery, BSMMU
}

\begin{abstract}
Patient and the general people expect that doctors remain up-to-date and professionally competent. The formal undergraduate and postgraduate education and training are conducted to bring a behavioral change in a medical practitioner to meet that expectation. The rate and magnitude of change in medical science is such that the contents of text books are not sufficiently up-to-date rather somewhat out of date at the time of publication. CME is continuing education in knowledge and skill of medical practice through which doctors will remain upto date. Due to rapid changes in health care delivery system; health professionals needs to transform from a continuing education (CME) to a continuous professional development (CPD) model so that they remain "up-todate" in their knowledge and competency in total care. CPD is a broader concept for continuing development of multifaceted competencies inherent in medical practice including medical, managerial, social and personal subjects which are needed for high quality professional performance in modern health care delivery system. CPD is complementary to formal undergraduate and postgraduate education; completing the educational trilogy. Undergraduate and postgraduate medical education is regulated by specific rules and regulation but CPD is the process where the responsibility rests on professionals and individual doctor. People expect what is 'best' rather than what is 'right' for a particular situation and for that level; professional competence should be combined with improvisation and general oversight. That is why, all over the world the concept of CPD is emerging and developing as a dynamic educational process to improve and upgrade ones professional performance. As a part of the 'global resident' we should be familiar to cope with and should be trying to contribute in these progress and development. This article will help us to initial understanding and formulating an approach to that.
\end{abstract}

\section{Introduction}

The members of various professional organizations all over the world are trying to change the behavioral aspect of their performance in the professional field. ${ }^{\mathbf{1}}{ }^{2}$ Internationally there is a move to continuous professional development (CPD) from continuing medical education (CME) model by the members of medical profession, to include the development of managerial, social, and other personal skills. ${ }^{3}$ Patient and the general people expect that doctors remain up-to-date and professionally competent ${ }^{4}$. The goal of Medical Education is to deliver improved and high quality health care to all people. The formal undergraduate education and postgraduate training with education are conducted under specific rules and regulations ${ }^{5}$ to bring a behavioral change to attain that goal. As the behavioral change depends on the personal perception of one's capabilities for performance or 'self efficacy perception', it is important to upgrade the capability for performance towards the highest level' ${ }^{6}$. So to remain up-to-date and upgrade the competence we need a self directed practice based learning activities; an informal and unsupervised training. The medical practice is considered as routine and predictable but in fact; doctors require making judgments in complex and unpredictable situations. People expect what is 'best' rather than what is 'right' for a particular situation and for that level; professional competence should be combined with improvisation and general oversight ${ }^{2,5,7}$. That is why, all over the world the concept of CPD is emerging and developing as a dynamic educational process to improve and upgrade ones professional performance.

CPD is the educational process by which members of any profession maintain, improve and broaden their knowledge, skill and personal qualities required in their professional life ${ }^{8}$. It is a holistic commitment to structured skills enhancement and personal or professional competence ${ }^{9,10}$. CPD can also be defined as the conscious updating of professional knowledge and the improvement of professional competence throughout a person's working life. It is the key to optimizing a person's career opportunities, both today and for the future ${ }^{\mathbf{1 1}}$. World Federation of Medical Education has defined the continuing professional development (CPD) for medical practitioners as the period of education and training, commencing after completion of basic medical education and postgraduate training and thereafter extending throughout each doctors professional working life. Both broad based knowledge to identify the areas of new competence and need based focal learning 5 . CPD is a combination of approaches, ideas and techniques that will help someone to manage ones own learning and growth $^{11,12}$. Ideally CPD should begin not only after the post graduation; it should be a continuous process for acquisition of knowledge and skill throughout the learning period and should start from beginning of any professional education; to be continued throughout the professional carrier ${ }^{3,5}$. In this article I have tried to analyze the concept of continuing medical education (CME or clinical update) and continuing professional 
development (CPD) in medical profession as it is evolving for the improvement of the quality to service delivery in the field of health care. As a part of the 'global resident' we should be familiar to cope with and should be trying to contribute in these progress and development. This article will also help us to initial understanding and formulating an approach to that.

\section{The definition of CME and CPD}

CME is continuing education in knowledge and skill of medical practice. All doctors need some other skills beyond medical knowledge and skill to practice effectively in modern health care delivery system. CPD is a broader concept for continuing development of multifaceted competencies inherent in medical practice including medical, managerial, social and personal subjects which are needed for high quality professional performance. CME is becoming one of the components of $\mathrm{CPD}{ }^{3,5,13}$. The CPD is the integration of CME with other quality improvement initiatives ${ }^{\mathbf{1 4}}$.

Now a day the CPD is considered as an essential component of education and is complementary to formal undergraduate and postgraduate education, completing the educational trilogy ${ }^{5,7}$. Due to rapid changes in health care; health professions are transitioning from a continuing education (CME) to a continuous professional development (CPD) model so that practitioners stay "up-to-date" in their knowledge and competent in total care $^{2,15}$. Undergraduate and postgraduate medical education is regulated by specific rules and regulation but $\mathrm{CPD}$ is the process where the responsibility rests on professionals and individual doctor ${ }^{5,16}$.

\section{Need for CPD}

In adult education; research has shown that the changes of behavior and practice depend on how and why someone learns rather how and why they are thought ${ }^{17}$. The need for CPD is very nicely explained by Sayeed farooq with the statement of the Dean of Harvard Medical School in 1947; quoted by Charlton as follows: "The rate and magnitude of change is such that the contents of text books are out of date at the time of publication. Indeed, probably half of what you know is no longer true but what troubles me more is that I don't know which half it is"18.

As a professional, we have a responsibility to keep our skills and knowledge up to date ${ }^{\mathbf{1 2}}$. The credibility of our profession is based on the willingness of each professional to embrace new skills, knowledge and experience. All career grade doctors need skills that extend beyond updating their medical knowledge in order to practice effectively in the modern health care. Such skills include management, education and training, information technology, audit, communication, team building and others. Individual doctors have a corporate responsibility through clinical governance and a personal responsibility to maintain clinical standards and performance. As a profession we all need to be self confident enough to embrace a culture of continuing education and development, peer review, appraisal, and revalidation ${ }^{2,7,13,16}$. Therefore CPD should go beyond the acquisition of knowledge and aim to impact on performance.

\section{The benefits of CPD \\ Personal benefits}

CPD is an investment that we make in our self for accelerating our carrier. It helps doctors to improve their professional effectiveness and career opportunities. It will boost our confidence and strengthen our professional credibility to prepare us for greater responsibilities and we can see our progression by tracking our learning. It will help us to be more creative in tackling new challenges and we will be able to cope positively with change by constantly updating our knowledge and skill. With CPD we will be able to identify our gap in knowledge and experience. CPD makes our working life more interesting and can significantly increase our job satisfaction and prevent 'burn out',12, 19

\section{Organizational benefits}

As organizations shift the responsibility for personal development back to the individual, the ability and insight to manage our professional growth is seen as a key strength. CPD will maximize staff potential by linking learning to actions and theory to practice. This leads to better staff morale and a motivated workforce helps give a positive image or brand to organizations. This is a good tool to help employees focus their achievements throughout the year ${ }^{12}$.

\section{Community benefit}

CPD contributes to improved patient healthcare and to a healthier society and the ultimate aim is to delivery a high quality care to the community ${ }^{4}$. 


\section{The CPD processes}

CPD is not a fixed process; it is a continuous learning and development rather than targeted intermittent input ${ }^{5}$. The first thing we can do is to develop a personal development plan (PDP) by setting objectives for development and then charting the progress towards achieving them ${ }^{4,19}$, and 20 .

Individual doctor's way of taking part in CPD will depend on their specialty, the opportunities available, their priorities and their personal learning styles and preferences. This diversity is essential for effective CPD ${ }^{13,14}$.

The following five step cyclical processes for CPD is useful to begin with ${ }^{\mathbf{7}, \mathbf{1 6} \text {, and } 21}$.

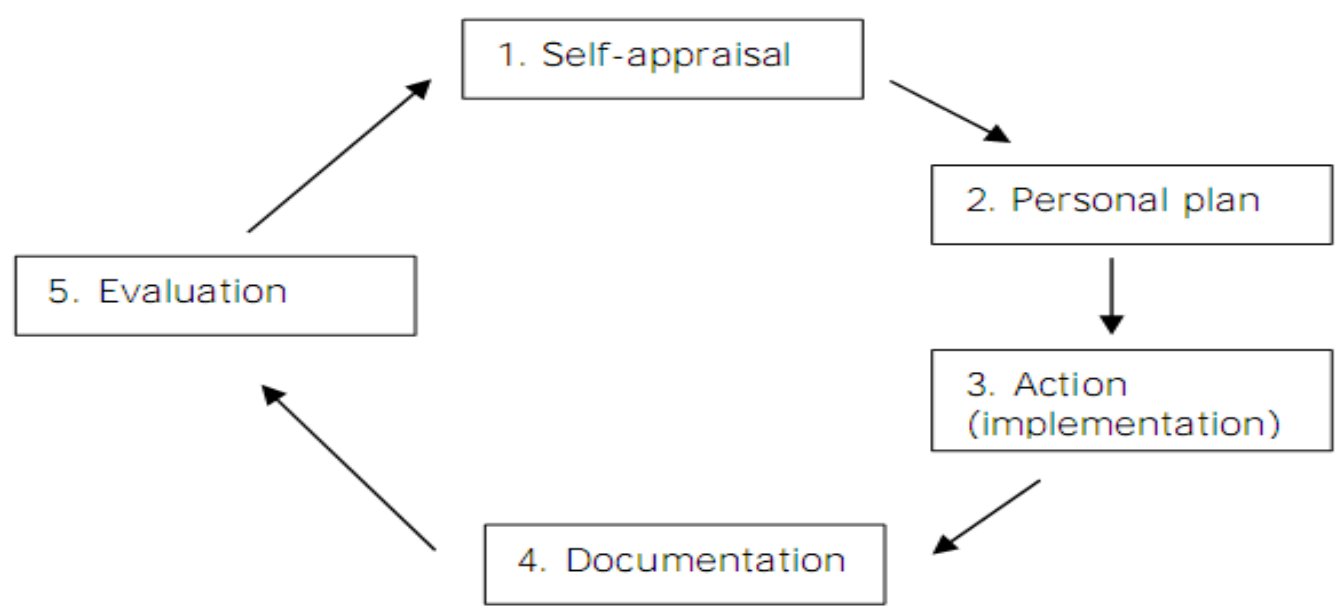

Ref. 7

\section{Self appraisal}

The assessment of learning need should be the first thing and the needs can be addressed either from self assessment of performance, performance reviewed by professionals/peer or from professional/employer and or regulatory binding as a requisite to future promotion ${ }^{21}$. The process should involve four stages: firstly the doctor estimates where he or she ought to be in terms of knowledge, skill, and performance related to the change. Secondly he or she also makes an estimate of what he or she presently knows or is able to do in terms of the image of change. Estimation of the discrepancy between what he or she ought to know or do and what he or she currently knows or does is the third stage and finally the he/she should experiences a level of anxiety because what is known or done does not match what ought to be ${ }^{17}$.

\section{The personal development plan (PDP)}

The PDP is written documents or portfolio for work based learning which identify the key learning objectives for a defined period ahead ${ }^{4,13,18,22}$. A strategic planning method can be used to evaluate the Strengths, Weaknesses, Opportunities and Threats (SWOT) involved in the PDP ${ }^{23}$. It involves specifying the objective with action required to achieve that, identifying the internal and external factors that are favorable and unfavorable to achieving that objective, identification of resources and training course. Research into information, literature, references to support our knowledge and identification of peer/colleagues who can provide advice for our PDP development and advancement ${ }^{21}$.

The PDP primarily depends on the need. The need means that the CPD activities must be a mixture of learning which is relevant to the current and or future practice and will benefit service user ${ }^{\mathbf{1 5}}$. There is one interesting thing that what we need to learn and what we want to learn varies. We must want to learn really what we need to upgrade and improve our competence for high quality patient care ${ }^{4}$. 


\section{Action}

The PDP is brought into practice by attaining professional qualifications, reading and or conducting research, informal discussion with colleagues, participation in professional body working groups, attending training courses and mentoring/guiding/work-shadowing of others ${ }^{21}$.

\section{Documentation}

CPD activities should be documented for evidence of competence, for appraisal of planning, action and systemic evaluation to review and inspection ${ }^{21}$. A continuous up-to-date and accurate record should be maintained ${ }^{15}$. At least once a year learning should be reviewed and to set further development objectives for the coming year. Reflecting on the past and planning for the future in this way makes the development more methodical and easier to measure ${ }^{12}$.

\section{Evaluation}

Benefit of any activities should be evaluated by possible questions like; 'were my need addressed? Can I address what I learned, how will my work improved? What else can I do to support my learning? ${ }^{\mathbf{2 1}}$ It is not important what is done but how we have utilized what is learnt. 'What can I do now that I couldn't do before?' is the question $^{12}$.

\section{The methods of learning in CPD}

The most effective personal development is from the experiences that one develop from own success and failure in everyday challenges. Setting aside some time daily or weekly to reflect on what is done and the plan to develop is good but it can be incorporated in the way of work. Actually many of us are doing CPD without realizing it. The thing is to have a planed approach and 'feeling the benefit ${ }^{\text {, }}$. So nothing to be worried about if you are too busy!

The method of learning is less important than its need ${ }^{5}$. Three interconnected systems are used; self directed curriculums, small group interaction, and organizational learning. All may include formal traditional programs and informal continuing educational (CE/CME) methods ${ }^{17}$.

The self directed curriculum, consists of three stages ${ }^{17,25}$. In stage one learning is directed toward understanding and estimating personal levels of need to learn in order to adopt a change in practice (self appraisal and PDP). Then learning the new competencies is the second step and thirdly adapting the new knowledge and skill to bring change in practice (action and documentation).

In small group peer interaction the practitioners will be able to identify gaps and will be able to change practice with the light of evidence and learning is guided by peer facilitator ${ }^{27}$.

Organizations can learn and help to learn and that learning can be enhanced by changes in organizational structure and climate. Watkins and Marsick define a learning organization as one that provides continuous learning opportunities, supports collaboration within the organization, and fosters links between the organization and other relevant organizations and individuals outside the organization to promote its effectiveness and establish its place in society ${ }^{\mathbf{2 6}}$. Whatever may be the method the aim is to bring changes in practice $^{\mathbf{1 6}}$ ?

\section{Organization of CPD program}

The CPD programme should be designed in such a way that it will promote a culture of curiosity and lifelong learning. It should include all possible range of educational process to meet the identified learning needs through self learning to attending CME as well as acquisition of professional skill ${ }^{4}$. Another point should be kept in mind that adult education is not merely the teaching by instruction but mostly by facilitation of learning ${ }^{17}$. The vast majorities of doctors are good learners and have always just got on with their own continuing medical education and professional development that is what being a professional means. However, the changing political and social climate and need to be more accountable mean that doctors now have to demonstrate that they are developing professionally and that their activities are educationally cost effective and improve their practice $^{13}$. 


\section{CPD activities}

CPD activities are all the activities that doctors undertake formally and informally in order to maintain, update, develop and enhance their knowledge, skill and attitude in response to the needs of their patients. Much of this development is informal and unconscious ${ }^{5}$.

Types of CPD activities $3,4,15,27,28$

\section{Work based learning}

Learning-by-doing is a concept where the capability of workers to improve their productivity by regularly repeating the same type of action. The increased productivity is achieved through practice, self-perfection and minor innovations. Few examples of the process are case studies, reflective practice, clinical audit, coaching from others, discussion with colleagues, peer review, involvement in wider work with employer (being a representative on a committee); work shadowing, journal club, in service training, supervising staff or student etc.

\section{Professional activities}

Involvement in a professional body with or without membership, teaching and lecturing, mentoring, being an examiner/ tutor/ national assessor and supervising research are one step ahead in CPD activities. Organizing journal club and other specialists group, maintaining and developing other extracurricular skills, giving presentation in conferences and organizing accredited courses are responsible works and carries further credit.

\section{Formal Educational courses}

Attending courses for further education and research can be the effective way to improve competences.

\section{Self directed learning}

Attending conferences and seminars, writing articles or papers, reading journal or articles which are not easily verifiable are the personal and self directed learning process. Updating knowledge through the internet or distant learning and keeping a file of the progress is one of the effective means to keep pace.

\section{Others}

Voluntary involvement in public service works and in mass educational courses is also important in developing extracurricular skills.

\section{Discussion}

Developing a CPD plan in any developing country is not so easy where the people's expectation is going up high and capacity to purchase service is very limited. There is no regulatory or legislative binding in requirement for CPD and there is enormous workload resulting lack of time for CPD in almost all developing countries. These factors should not be the excuse for lack of CPD. It must be considered an important strategy to cope with the problems rather than just an individual need. The continuing medical education activities organized by the various professional bodies in these countries can be a starting point for the CPD programme. These activities, however, need to be guided by a planned educational policy suitable for a particular country or region $^{18}$.

Research has shown widespread barriers to the successful planning, participation in and recording of CPD for doctors. Individual doctors' information needs need to be addressed, but organizational support for CPD is also required $^{\mathbf{2 0}}$. This requires the development of skills in training the trainers, working effectively with other disciplines, particularly primary care, and developing partnerships with the traditional healers who care for large populations. Regional and international collaboration supported by the use of information technology is also needed $^{18}$.

CPD credit is increasingly becoming important all over the world ${ }^{\mathbf{4}} \mathbf{2 8}$, and ${ }^{29}$. Europe, USA and UK have agreed on minimum criteria for CME. European Accrediting Council for CME (EACCME) is a body to approve the provider in their area. In UK the Royal Colleges have taken the responsibilities for professional development of hospital doctors with parallel arrangement for general practitioners. Currently it is based on acquiring credit ${ }^{\mathbf{1 3}}$.

Academy of Medical Royal College is a designated national authority for CPD in UK having their directors of CPD group ${ }^{4}$. The GMC declared the necessity of license for practice from November 2009 and will be 
revalidated for all registered practitioners periodically ${ }^{2}$. CPD is counted as a new responsibility for the doctors and the health professional council (HPC) is there to set standard of CPD and keep register of health professional who meet the standard and they (HPC) will perform an audit for CPD standard, for renewal of the registration ${ }^{15}$. In July 2007 CPD is approved by the medical and dental council of Nigeria ${ }^{28}$.

The CPD activities are classified for credit measurement as personal, internal and external by GMC. There must be 10, 25 and 15 credit respectively in each year and 25 external nonclinical credits over 5 year. The personal activities include the item the benefit of which is determined by the individual and not verifiable by audit. These are reading journals, self development using enduring materials (print, CD Rom, or web based materials; possibly based on a curriculum, with testing or assessment), to be incorporated as acreditor, to be an examiner or resource personal etc.

The internal activities are routine local activity with colleagues and can be arranged for verification. Consultation with peers and colleagues, medical meeting in the hospital, grand round, journal club, research and publication, arrangement and management of CPD, practice based activities, case discussion are few example in this category.

External or live activities are readily verifiable and auditable programs like; local, regional, national and international conferences, seminars and workshops, revision and updates courses, meetings with audio and video presentation. Practice based small group (PBSG) learning is gradually becoming more popular and effective in many country ${ }^{4}$.

The effective CPD is that one which encourages and motivates learning and must contribute high quality patient care and must be relevant, measurable and verifiable ${ }^{4,29}$.

The improved patient care is the key to asses the effective CPD and it can be done with self audit on the basis of previous performance or against the set guideline. Peer review in the best one to asses and further planning. There are established tool to asses various competence such as multisource feedback and patient satisfaction questionnaire 4 . Widely used methods like seminars have little direct effect on improving professional performance. Systemic practice based interventions and outreach visit are among most effective methods but seldom used by the CME providers ${ }^{30}$.

Three factors make the CPD effective; number one is the need or reason is identified for a particular CPD, learning is based on that identified need or reason comes next and the third but most important is a provision of follow up for reinforcing the learning ${ }^{5,31}$.

CPD can also be made effective through set responsibilities of the learner (Doctor), CPD provider, utilizer and acreditor. The most important factor is that the learners should be motivated to be an efficient professional to deliver the highest quality service to an individual patient ${ }^{\mathbf{1 4}}$. The desire comes from their personal lives, professional aspirations, and the social and cultural environment of their practice settings. The factors to develop the desire are curiosity, sense of personal and financial wellbeing, stage of career, attraction for new or enhanced competence, pressures from patients and colleagues, and pressures from the healthcare institutions ${ }^{17}$. The need to preserve job satisfaction and to prevent 'burn out' is the other factor to be motivated' ${ }^{5}$. Professionals can be motivated for the CPD process by recording credit for yearly appraisal and revalidation from accrediting or regulatory authority which is one of the major ways of motivation used in many countries ${ }^{\mathbf{4 , 1 9}}$.

Different forces seemed to scatter doctors in different directions. Personal forces were associated with larger and more complex changes, professional and social forces with smaller and simpler changes. Regulations were associated with only small accommodations, which were usually made with resentment. ${ }^{17}$

CPD provider and utilizer can be from an individual doctor to multinational CPD provider. The medical professional organizations should take the responsibility to guide for the quality, overall planning and organization of CPD. CPD provider should provide the learning activities which are most effective ${ }^{5}$.

Accrediting body should take the responsibility to ensure quality and standard either by accrediting the provider or each educational event ${ }^{5}$.

\section{Conclusion}

We need to improve our self to cope with the changing working environment. As an adult learner the effective CPD programme and the guideline for us is still wanting for our country. And for that we need to find out the answer of many basic questions like what is the attitude of our doctors for life long learning and how they think 
to change their practice. How and why they will be motivated to take positive steps to CPD. As there is no definite guideline from the regulatory body or the policy maker authority in many developing countries like ours; the professional organizations should come forward to formulate the research to provide informations for developing a motivation in personal and organizational level and should develop a guideline and implement the CPD programme among the members. And the most important is that there should be a combined and collaborative effort to convince, motivate and guide the policy makers and accrediting authority.

\section{References}

1. O ANZI Coaching. Guide to writing CPD article. Dec 2007. V 1, 2-5. http://anzicoaching.com/pdf/Guide\%20to\%20Writing\%20CPD\%20Articles.pdf

2. V Royal College of General Practitioners. RCGP Guide to Revalidation of General Practitioners. Ver 3 January 2010.

3. Q Peck C, Martha M, McLaren B, Rotem T. Continuing medical education and continuing professional development: international comparisons. BMJ Feb 2000;320:432-435.

4. A Strake I, Wade W. Continuing Professional development-supporting the delivery of quality health care. Ann Acad Med Singapore 2005; 34:714-9.

5. B World Federation of Medical Education. Continuing Professional development of Medical doctors, WFME Global standard for quality improvement. WFME Copenhagen 2003. http://www.wfme.org

6. M Cervone D. Thinking about self efficacy. Behav Modif, vol.24, No. 1, January 2000. 30-56. DOI: 10. $1177 / 0145445500241002$

7. J General Medical Council; Guidance on CPD 2009. http://www.gmcuk.org/education/continuing_professional_development/cpd_guidance.asp

8. AA Royal College of Physician. CPD overview, what is CPD? http://www.rcplondon.ac.uk/education/cpd/Pages/cpd.aspx . viewed on 02/04/10

9. C Wikipedia. Continuing Professional development. Last modified on 27 February 2010. http://en.wikipedia.org/wiki/Continuing_professional_development .

10. D Royal Society of Chemistry 2010. A guide to CPD http://www.rsc.org/Education/CareersAndCPD/CPD/CPDguide.asp 01/04/10.

11. E DTI (2002). Accelerating Change. Web document. http://www.strategicforum.org.uk/pdf/report_sept02.pdf o1/02/10.

12. F The Chartered Institute of Personnel and Development (CIPD). http://www.cipd.co.uk/cpd/aboutcpd/whatiscpd.htm viewed on 10/04/10.

13. I From CME to CPD: getting better at getting better? Editorials. BMJ 2000; 320(7232):393 (12 February), doi:10.1136/bmj.320.7232.393.

14. W European academy of teachers in general practice. Continuing professional development; integration of formal CME and quality improvement initiative. http://www.degam.de/dokumente/cpd.pdf viewed on 02/04/2010.

15. G Health professions council. Your guide to our standard of continuing professional development (2009). http://www.hpc-uk.org/assets/documents/1000119FShort_guide_to_CPD.pdf.

16. R Little P and Hayes S. Continuing professional development (CPD): GPs' perceptions of post-graduate education-approved (PGEA) meetings and personal professional development plans (PDPs). Family Practice 2003; 20: 192-198. 
17. BB Fox RD, Bennett NL. Continuing medical education: Learning and change: implications for continuing medical education. BMJ 1998;316:466-468.

18. P Farooq S. Continuing professional development for psychiatrists in developing countries. Advances in Psychiatric Treatment (2003) 9: 161-163.

19. S Editorials. Revalidation for doctors; should reflect doctors' performance and continuing professional development. BMJ 1998; 317:1094-1095. http://www.bmj.com/cgi/content/full/317/7166/1094 ( 24 October )

20. T Lloyd-Williams M, Kite S, Hicks F, Todd J, Ward J, Barnett M. Continuing Professional Development (CPD) in palliative medicine: a survey. Medical Teacher, Vol 28, Issue 2 March 2006; 171 - 174.

21. Z Regulatory affaires professional society. EIPG guidance on CPD for RA. Viewed on 01/04/ 2010. http://www.eipg.eu/records/EIPG\%20Guidance\%20on\%20CPD\%20for\%20RA\%20Rev\%20Oct\%2009.p df.

22. CC Holloway J. CPD portfolio and PDP why and how? Advances in psychiatric treatment. 2000. Vol 6; pp 467-475.

23. L Wikipedia. SWOT analysis. Last modified on 24 March 2010 http://en.wikipedia.org/wiki/SWOT_analysis.

24. Bennett NL, Casebeer LL. Evolution of planning in CME. J Continuing Educ Health Professions 1995; 15:70-9.

25. Senge P. The fifth discipline. New York: Doubleday, 1990.

26. H BC Presentation ply ltd. CPD guide for the accrediting building practitioners. Ver 1.2 June 2007. www.bcpresentations.com.au

27. U Armson H, Kinzie S, Hawes D, Roder S, Wakefield J and Elmsie T. Translting learning into practice; lessons from the practice based small group learning program. Can Fam Physician 2007; 53:1477-1485.

28. Y MEDICAL AND DENTAL COUNCIL OF NIGERIA. General Guidelines on Continuing Professional development 2007. http://www.mdcnigeria.org viewed on 02/04/2010.

29. X Certified General Accountants Association of Canada. Continuing professional development standard. CGA Canada. Ver 1 march 2005. Viewed on 02/04/2010. http://www.cga-canada.org/enca/OtherDocuments/ca_int_cpd_standard-v1-Feb2009.pdf viewed on 02/04/2010.

30. N Davis DA, Thomson MA, Oxman AD, Haynes RB. Changing Physicians Performance; A Systemic Review of the effect of Continuing Medical Education Strategies. JAMA, September 6, 1995 Vol 274 No 9, 700-705.

31. K Grant J, Chambers E, and Jakson G. The good CPD Guide. Read Healthcare Publishing. Sutton, 1999.

\section{Address of correspondence: \\ Dr M A Wohab Khan}

Associate professor

Department of Surgery

BSMMU. C/916.

Cell- +8801711521064

drkhan@bangla.net 